\title{
THE SCIENCE OF AWE: HOW CULTIVATING WONDER BOOSTS YOUR HAPPINESS AND HEALTH
} Interview by Uliana Lushch-Purii

In Happiness And Contemporary Society : Conference Proceedings Volume (Lviv, March, 20-21, 2021). Lviv: SPOLOM, 2021. P. 220-223. https://doi.org/10.31108/7.2021.50

ISBN 978-966-919-697-2 
https://doi.org/10.31108/7.2021.50

\author{
PAQUETTE Jonah \\ Psy.D., the Assistant Regional Director of Mental Health Training at HMO in \\ the San Francisco Bay Area, Author, International Speaker (USA)
}

\title{
THE SCIENCE OF AWE: HOW CULTIVATING WONDER BOOSTS YOUR HAPPINESS AND HEALTH
}

\author{
Interview by Uliana Lushch-Purii
}

Uliana Lushch-Purii, PhD, Associate Professor, Co-founder of The Ukrainian Institute for Happiness Research: What are the main ideas of your newest third book published last year on the science of awe?

For the past, I would say, almost decade of my life I've been focusing more generally on this idea, this ancient timeless question of how do we become happier and how do we help the people that we love and the people that we work with to become happier as well. My previous works, and talks, and other things I do were focused a little bite more broadly on happiness, focusing on principles like gratitude, and mindfulness, self-compassion, acceptance and other principles for well-being. But in a last couple of years I've gotten really interested in this new area of the field, the newest, hottest, freshest area of the research, in my mind, at least, which is how these moments of awe and wonder can really change our lives. So my most recent book which came out about six months ago called Awestruck (2020) focuses on all of that research that is very cutting edge, it looks like at everything from the impact of awe and wonder on our mood, our stress, but also on our body and our brain, so looking at particular impacts on our nervous system, on our immune system response. It turns out that these moments that give us goosebumps, that make us go: "Wow!" - can really change our lives in these incredible ways. That is what my book speaks to all of the researches that points out how powerful those moments of awe and wonder could be for so many parts of our lives: for our relationships, for health and for happiness, certainly.

Uliana Lushch-Purii: It seems to me that when we speak of wonder and awe, does it mean that, all of us, we need to be a bit philosophers, we need to be those who are capable for wonder, because actually all the everyday life routines do not allow us to wonder about things and to dedicate time for this feeling of awe. Does it mean that we need to get to philosophizing a bit?

I think it means a few things but first of all it means that we all need to pause, to step back and to train our brain to notice all of the amazing things that are happening around us that we so often miss, take for granted because of how busy everyday life can be. Just the very fact that you and I are having this conversation in real time - where you are and where I am - is pretty incredible if you think about it. But I think we all go through life, many of us, at least, taking much of it for granted, for example, running water, a bad to sleep on, electricity, the Internet, the natural beauty around us. To me it's so much about how do we notice the small parts of life that are really magical but that we so often miss. I think it might be useful to also think about what do we mean in this 
research when we say "awe" and "wonder". There's a lot of definitions that are out there, but the one I particularly like is: it's the feeling that we get when we are in the presence of something bigger than ourselves that challenges what we thought we know about the world. We can experience this in nature, but we can also experience it through technology, we can experience it through inspiring people that we admire and we feel uplifted by. We can experience a sense of wander when we just stop and reflect on how unlikely for us is to even exist in this moment: all of those things that had to happen just perfectly for the last tens of thousands of years for us to even have this breath, to have this moment, to have this experience - and that's really mind-blowing if you think about it. When we look up at the night sky, when we gaze up at the Sun or the Moon. I would say that one of the main messages of my book is that we can certainly experience awe and wonder in this very grand, large-scale experiences, but so much of it is really about finding it in small parts of life, finding the awe that exists right under our noses but that we do not often pause long enough to really view that way.

Uliana Lushch-Purii: So as I understand, we need to train our brain to feel positive experience, to get used to feeling and living through this positive experience.

Yes, and it's a very similar principle for any of the happiness skills that we talk about. The more we experience something that way on a brain-based level, that's mindful awareness, gratitude, compassion or kindness, the more we engage those parts of the brain, the more likely that we are to experience them again. When we even imagine experiencing things - let's say you had a lovely experience of wander a month ago even when you just reflect on it, recall it, it has many of those same reactions in your brain and throughout of your body as when it was really happening. So that's another aspect of this: we do not want just to turn off the page, we do not want to just move on to the next thing, we want to linger with, replay it, relive it and reactivate the neural circuit that is a big part of this experience as well.

Uliana Lushch-Purii: You emphasize on the lasting and sustainable happiness. There are lots of people who do not have a deep scientific knowledge on happiness who follow a popular view that happiness is something like a moment that does not last long and you cannot maintain this experience, it's something that comes and goes and there's nothing to do with that. So what could you say about this lasting happiness as a process?

That's a great question because I think when you say a word "happiness", so many people have the idea that's very brief, very fleeting and also not particularly deep experience, almost like a sugar rush: you feel good for a moment and then it's gone. My work, my writings and the lectures that I give focus a lot more on how do we build something that's sustainable and lasting and it really changes our lives. It does not mean feeling good all the time, it doesn't mean each day feels pleasant. It means that we live life from the place of resiliency, from the place of strength, from the place of doing things that are meaningful to us, that give us a sense of purpose, belonging and connection. I'd like to think of layers of happiness and different ingredients. There is the part of it that has to do with feeling good, but there's also this part that has to do with living well and doing things that give us a sense of meaning and purpose and belonging that's much deeper, more solid ground. Even though life is going to give us challenges and we are going to have good days and bad days, we can still be living that truer place of greater well-being. 
Uliana Lushch-Purii: Completely agree with you, indeed. We live in a very challenging period of Covid-19 quarantine restrictions and many people have actually lived through a very complicated experience of this disease. So from your psychological practice experience, does this challenging experience of the disease help a person to focus on wonder and awe experience? Surviving the life-threatening disease, does it help to improve skills of wondering?

That's a wonderful question. It certainly can, I think, because it gives us an opportunity to shift from living life when we just go through emotions and we focus just on day to day stress to a much deeper perspective. You can imagine either as a society coming out of something as Covid-19 or an individual who heals from it, the potential that gives us to notice the amazing things around us that we normally don't even take time to notice, the potential that that gives us to really value the sense of connection to people that we love and to realize how precious those relationships are, the potential that it gives us to feel a greater sense of gratitude for what we do have because it could be so easily lost, the opportunity it has to feel inspired by other people who have done so much to fight this virus, the opportunity this experience give us to notice just how wondrous the world is around us in part because we were so close to losing it - that is the layer when we realize how fragile our existence is, our relationships are and how much our life is tenuous in that way. It really does give us the opportunity to see things in this much more precious light, something to be cherished.

Uliana Lushch-Purii: It's complicated, because it's different in each individual case, but still: are there any tools, advises for people not to get depressed after surviving the disease and, maybe, losing some ability/condition they've had before, but to focus on awe, wondering and appreciation?

First, we want to give people lots of room and space to feel whatever they feel, and people have been affected by the disease in so many devastating ways. We do not want to just jump immediately to "well, let's focus on the things that are good and parts of life that are wonderful". We need to have both. A lot of messages in my work is that if we want to find balance. We do not want to pretend like problems aren't there but we also do not want to live only in those problems. We've talked earlier a bit on neuroplasticity and our brain's tendency to change based on experience. When we only ruminate and dwell on and focus on the bad parts in life, we end up spiraling down deeper and deeper into those places. We have to find the way to stop that process and to balance it up with a different perspective. I go back to many principles that I write about, I focus on ten core principles for well-being, awe is one of those that I'm really passionate about as well these days. But I think there's so many ways that we can break that cycle whether it is focusing on the things that give us a sense of wander and awe, whether that's stepping out of our own struggles by being there for another person - that's compassion towards others that often helps to heal ourselves -, focusing on those close social connections that we do have and how do I invest in that as opposed to focusing on the parts of my life that I don't have, taking care of our body, the food that we eat and the habits that we engage can be a big part of this as well. So every day we have this choice of do we want to give in to the negative parts of our experience and feed that side of things, or do we want to develop, build and cultivate a capacity for joy, a capacity for meaning, a capacity for engagement, for connection - and we are always going to have both, it's always a question, it's more of a question of each day, what am I going to add more fuel to, what 
am I going to focus more on. And that's what we have some power of: we cannot control the things that happened to us in life but the way we respond to that, to some level, at least, is one of a few things that we actually can do something about them.

We talked about what awe is and ways we might be cultivate it, but I think many of the attendees of this conference might be especially interested to know a little bit more about the benefits that we experience when we have these moments. We think of these moments as very brief - for just a few seconds - but I think there's the amazing affect that it has in ways both short-term as well as longer-term that speak to its power. So psychologically speaking we now know that when we experience awe or wander it makes us happier, its boosts our mood, it lowers rates of feeling depressed, it reduces feelings of stress; and on our physical level it's strengthens our social connection, so people who experience awe feel closer to the other people in their lives and it makes people kinder, more altruistic, more giving towards others. So there is a lot of interpersonal as well as psychological benefits to it. And then, when you look what's happening physiologically, to me, one of the coolest findings is that when we experience these moments of wander and awe it actually reduces the markers of chronic inflammation in our body. Chronic inflammation is linked to depression, in particular. Awe is more than other emotions that's been studied reduces markers of chronic inflammation, it actually heals our body, it changes our brain - the default mode network that tends to be very active when we are ruminating and worrying. When we are wandering, it decreases the activation of this mode, we become much more present, much more engaged with life that's right in front of us as opposed to our mind bouncing in a hundred different ways. There's a lot more benefits to that, but I think in 2020-2021 when we feel lonelier than ever before, when we feel more stressed than ever before, there're records of a high rate depression, it's amazing to me that awe actually seems to target many of the things that collectively as a society and as a world we need to work on. It helps us go from being lonely to more connected, it helps us go from feeling stressed to more relaxed, and these moments of wander help us go from feeling depressed to more content in our lives.

Uliana Lushch-Purii: It makes me thing of people who, probably, refuse to feel awe. A few years ago I visited Synevyr lake in the Carpathian Mountains, there were lots of tourists there and while others were admiring the view of the lake, I remind myself of a man expressing very loudly his disappointment, he said that there was nothing to admire, it was nothing beautiful in it and he was, obviously ruining the experience of awe to his wife and children standing next to him. What should we do with such people?

There are some studies showing that even when we start at different point and it might be easier for some of us and more difficult for others to experience awe and wonder, it is almost like a muscle we can learn to develop and we can build. It's about training our brain, training our mind, build a habit to find beauty and wondrous and inspiring things in wherever we are in that moment of our life, but it takes time and effort. 